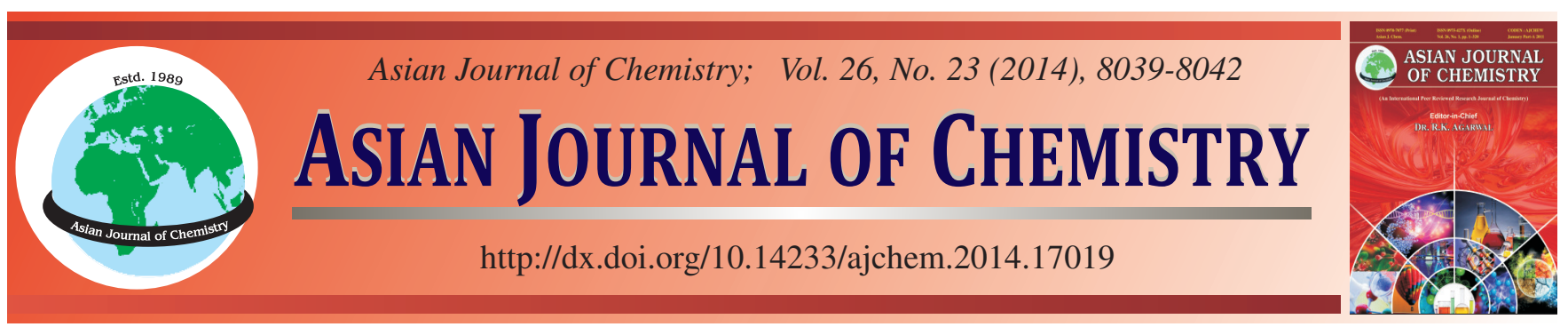

\title{
Selective Acylation of Phenols in Boron Trifluoride Diethyl Etherate Solution and the Mechanistic Implication
}

Zhu-Ping Xiao*, Wei Wei, Shen Huang, Xiao-Yi Lin, Bin Peng, Xu-Dong Wang and Lei Zhang

College of Chemistry and Chemical Engineering, Jishou University, Jishou 416000, P.R. China

*Corresponding author: Tel/Fax: + 8674 8563911; E-mail: xiaozhuping2005@163.com

Received: 10 January 2014;

Accepted: 10 April 2014;

Published online: 15 November 2014;

AJC-16289

\begin{abstract}
In the presence of boron trifluoride diethyl etherate $\left(\mathrm{BF}_{3} \cdot \mathrm{OEt}_{2}\right)$, direct acylation of phenols with free carboxylic acid is chemoselective and regioselective and no demethylation, if any, was observed. The para-directing effect of $\mathrm{BF}_{3} \cdot \mathrm{OEt}_{2}$ is attributed to the large steric hindrance of the boron trifluoride-phenolic hydroxyl group complex, which blocks the ortho-acylation from occurrence. Microwave irradiation could not change the regioselectivity of $\mathrm{BF}_{3} \cdot \mathrm{OEt}_{2}$ except the reaction time being greatly shortened.

Keywords: Regioselectivity, Direct acylation of phenol, Boron trifluoride diethyl ehterate.
\end{abstract}

\section{INTRODUCTION}

Hydroxyaryl ketones are versatile intermediates for synthesis of chalcones ${ }^{1,2}$, aryl pyrazoles ${ }^{3}$, flavonoids ${ }^{4,5}$ and alkyl phenols $^{6}$, which show interesting pharmacological properties including antiinflammatory, telomerase inhibitory and antimicrobial activities. In view of the preparation of hydroxyaryl ketones, the typical approach is cascade chlorination of a carboxylic acid, esterification with phenols and Fries rearrangement in the presence of a Lewis acid ${ }^{7,8}$. By comparison, a one pot acylation of a phenol with free carboxylic acids has attracted much interest ${ }^{9}$. Over the past decades, a method of direct condensation of a phenol with a carboxylic acid in the presence of boron trifluoride gas has been developed for this end and was used in several instances ${ }^{10,11}$. A variety of strategies have been proposed to modify this method, including substitution of boron trifluoride diethyl etherate $\left(\mathrm{BF}_{3} \cdot \mathrm{OEt}_{2}\right)$ for boron trifluoride gas ${ }^{12}$ and microwave-assisted condensation ${ }^{13,14}$. However, the selectivity and mechanism of these reactions are so far lacking in detail. Herein, we report our findings.

\section{EXPERIMENTAL}

All chemicals (reagent grade) used were purchased from Aldrich (U.S.A) and Sinopharm Chemical Reagent Co., Ltd (China). All microwave experiments were performed using an APEX microwave synthesizer (PreeKem, China). Melting points (uncorrected) were determined on a XT4 MP apparatus (Taike Corp., China). EI mass spectra were obtained on a Waters GCT mass spectrometer and ${ }^{1} \mathrm{H}$ NMR spectra were recorded on a Bruker AV-300 spectrometer at $25^{\circ} \mathrm{C}$ with TMS and solvent signals allotted as internal standards. Chemical shifts were reported in ppm $(\delta)$. Elemental analyses were performed on a CHN-O-Rapid instrument and were within $\pm 0.4 \%$ of the theoretical values.

Crystallographic studies: X-ray single-crystal diffraction data for compound $\mathbf{1 4}$ was collected on a Bruker SMART APEX CCD diffractometer at 296(2) $\mathrm{K}$ using $\mathrm{MoK}_{\alpha}$ radiation ( $\lambda=0.71073 \AA$ ) by the $\omega$ scan mode. The program SAINT was used for integration of the diffraction profiles. All the structures were solved by direct methods using the SHELXS program of the SHELXTL package and refined by full-matrix leastsquares methods with SHELXL. All non-hydrogen atoms of compound 14 were refined with anisotropic thermal parameters. All hydrogen atoms were generated theoretically onto the parent atoms and refined isotropically with fixed thermal factors.

\section{General procedure for acylation}

Method A: Phenol (12-15 mmol) and aliphatic acid (10 mmol) were dissolved into $10 \mathrm{~mL}$ of $\mathrm{BF}_{3} \cdot \mathrm{Et}_{2} \mathrm{O}$. The mixture was stirred and heated on the oil-bath at $80-90{ }^{\circ} \mathrm{C}$ for $2-4 \mathrm{~h}$. After cooling, the contents were poured into $200 \mathrm{~mL}$ of icecold aqueous solution of sodium acetate (w. $\%=10 \%$ ) with stirring. Then, the precipitate was filtered and washed thrice with water. The crude product was purified by a flash chromatography with EtOAc-petroleum ether ( $: \mathrm{v}=1: 2$ to 1:3) to afford colourless crystals.

Method B: Phenol (10 mmol) and aliphatic acid (20-30 mmol) were dissolved into $10 \mathrm{~mL}$ of $\mathrm{BF}_{3} \cdot \mathrm{Et}_{2} \mathrm{O}$. The mixture was stirred and heated on the oil-bath at $80-90{ }^{\circ} \mathrm{C}$ for $2-4 \mathrm{~h}$. 
After cooling, the contents were poured into $200 \mathrm{~mL}$ of icecold aqueous solution of sodium acetate $(w . \%=10 \%)$ with stirring. Then, the mixture was extracted with EtOAc and dried. After removal of solvent, the crude product was from EtOAcpetroleum ( $\mathrm{v}: \mathrm{v}=1: 1$ to $1: 3)$ to give colourless crystals.

Mthod C: The conditions and procedures are the same as method $\mathrm{A}$ or $\mathrm{B}$ except substitution microwave irradiation for heat and the volume of $\mathrm{BF}_{3} \cdot \mathrm{Et}_{2} \mathrm{O}$ being halved.

1-(3,4-Dihydroxyphenyl)-2-(4-fluorophenyl)ethanone (18): Yield $79 \%$ (86\% for microwave irradiation); m.p. 187$188{ }^{\circ} \mathrm{C} .{ }^{1} \mathrm{H}$ NMR $\left(d_{6}\right.$-DMSO): 4.23 (s, 2H), 8.82 (d, $1 \mathrm{H}, J=$ $8.4 \mathrm{~Hz}), 7.12(\mathrm{t}, 2 \mathrm{H}, J=9.2 \mathrm{~Hz}), 7.26(\mathrm{dd}, 2 \mathrm{H}, J=8.8 \mathrm{~Hz}, J=$ $5.6 \mathrm{~Hz}), 7.39(\mathrm{~d}, 1 \mathrm{H}, J=2.4 \mathrm{~Hz}), 7.47(\mathrm{dd}, 1 \mathrm{H}, J=8.0 \mathrm{~Hz}$, $J=2.0 \mathrm{~Hz}), 9.35$ (s, $1 \mathrm{H}), 9.89$ (s, 1H). EI-MS C ${ }_{14} \mathrm{H}_{11} \mathrm{FO}_{3}\left(\mathrm{M}^{+}\right)$ 246. Anal. calc. for $\mathrm{C}_{14} \mathrm{H}_{11} \mathrm{FO}_{3}$ : C, 68.29; H, 4.50; F, 7.72. Found: C, 68.37; H, 4.49; F, 7.71.

1-(3,4-Dihydroxyphenyl)-2-(4-chlorophenyl)ethanone (19): Yield $83 \%$ (95\% for microwave irradiation); m.p. 200$202{ }^{\circ} \mathrm{C} .{ }^{1} \mathrm{H}$ NMR $\left(d_{6}\right.$-DMSO): $4.24(\mathrm{~s}, 2 \mathrm{H}), 8.82(\mathrm{~d}, 1 \mathrm{H}, J=$ $8.0 \mathrm{~Hz}), 7.25(\mathrm{~d}, 2 \mathrm{H}, J=8.4 \mathrm{~Hz}), 7.36(\mathrm{~d}, 2 \mathrm{H}, J=8.4 \mathrm{~Hz})$, $7.38(\mathrm{~d}, 1 \mathrm{H}, J=2.0 \mathrm{~Hz}), 7.47(\mathrm{dd}, 1 \mathrm{H}, J=8.0 \mathrm{~Hz}, J=2.0 \mathrm{~Hz})$, 9.36 (s, 1H), 9.90 (s, 1H). EI-MS C ${ }_{14} \mathrm{H}_{11} \mathrm{ClO}_{3}\left(\mathrm{M}^{+}\right)$262. Anal. calc. for $\mathrm{C}_{14} \mathrm{H}_{11} \mathrm{ClO}_{3}$ : C, 64.01; $\mathrm{H}, 4.22 ; \mathrm{Cl}, 13.50$. Found: $\mathrm{C}$, 63.96; H, 4.22; Cl, 13.52 .

1-(3,4-Dihydroxyphenyl)-2-(3,4-dimethoxyphenyl)ethanone (20): Yield $86 \%$ (90\% for microwave irradiation); m.p. $179-181{ }^{\circ} \mathrm{C} .{ }^{1} \mathrm{H}$ NMR $\left(d_{6}\right.$-DMSO): 3.709 (s, 3H), 3.711 (s, $3 \mathrm{H}), 4.12(\mathrm{~s}, 2 \mathrm{H}), 6.74(\mathrm{dd}, 1 \mathrm{H}, J=8.0 \mathrm{~Hz}, J=1.6 \mathrm{~Hz}), 6.81(\mathrm{~d}$,
$1 \mathrm{H}, J=8.4 \mathrm{~Hz}), 6.85(\mathrm{~d}, 1 \mathrm{H}, J=1.6 \mathrm{~Hz}), 6.86(\mathrm{~d}, 1 \mathrm{H}, J=8.0$ $\mathrm{Hz}), 7.39$ (d, 1H, $J=2.0 \mathrm{~Hz}), 7.46(\mathrm{dd}, 1 \mathrm{H}, J=8.4 \mathrm{~Hz}, J=2.4$ $\mathrm{Hz}), 9.33$ (s, 1H), 9.86 (s, 1H). EI-MS $\mathrm{C}_{16} \mathrm{H}_{16} \mathrm{O}_{5}\left(\mathrm{M}^{+}\right)$224. Anal. calc. for $\mathrm{C}_{16} \mathrm{H}_{16} \mathrm{O}_{5}$ : C, 66.66; H, 5.59. Found: C, 66.59; H, 5.59.

\section{RESULTS AND DISCUSSION}

During our drug discovery program on the synthesis of polyphenols as urease inhibitors ${ }^{15-17}$, a series of hydroxyaryl ketones were designed and synthesized by direct condensation of phenols with carboxylic acids in $\mathrm{BF}_{3} \cdot \mathrm{OEt}_{2}$ according to the previous described method (Scheme-I) ${ }^{12}$. In comparison with phenol and pyrogallol, catechol not only has ortho-, metaand para-positions being available but also shows a good reactivity and was therefore selected to explore the chemoand regioselectivity.

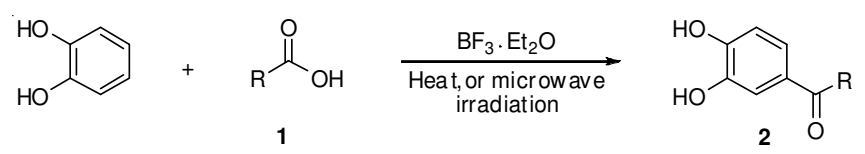

Scheme-I: Direct acylation of phenol with free carboxylic acid

First of all, a general reaction condition was explored and the results are shown in Fig. 1, which disclosed that a temperature of $90{ }^{\circ} \mathrm{C}$ was sufficient to complete the condensation reaction. This one pot procedure is particularly useful for preparing ketones with long chains and leads to uniformly high yields, usually in a range of 68 to $90 \%$ (Table-1). It is noted

\begin{tabular}{|c|c|c|c|c|c|c|c|}
\hline \multicolumn{8}{|c|}{$\begin{array}{c}\text { TABLE-1 } \\
\text { ACYLATION PRODUCTS OF PHENOL }\end{array}$} \\
\hline \multirow[t]{2}{*}{ Compound } & \multicolumn{3}{|c|}{$\mathrm{O}^{\mathrm{R}^{1}}$} & \multirow[t]{2}{*}{$\begin{array}{l}\text { Method/ } \\
\text { Yield (\%) }\end{array}$} & \multirow[t]{2}{*}{$\begin{array}{l}\text { Energy } \\
\text { (w) }\end{array}$} & \multirow[t]{2}{*}{ Time } & \multirow[t]{2}{*}{$\begin{array}{l}\text { m.p. }\left({ }^{\circ} \mathrm{C}\right) \\
\text { Found/Reported }\end{array}$} \\
\hline & $\overline{\mathrm{R}^{1}}$ & $\mathrm{R}^{2}$ & $\mathrm{R}^{3}$ & & & & \\
\hline \multirow{2}{*}{10} & \multirow{2}{*}{$\mathrm{OH}$} & \multirow{2}{*}{$\mathrm{OH}$} & \multirow{2}{*}{ Methyl } & $\mathrm{B} / 62$ & - & $2 \mathrm{~h}$ & $117-119 /$ \\
\hline & & & & $\mathrm{C} / 78$ & 300 & $2.5 \mathrm{~min}$ & $114-115^{18}$ \\
\hline \multirow{2}{*}{11} & \multirow{2}{*}{$\mathrm{OH}$} & \multirow{2}{*}{$\mathrm{OH}$} & \multirow{2}{*}{ Propyl } & $\mathrm{B} / 64$ & - & $2.5 \mathrm{~h}$ & \multirow{2}{*}{$139-140 / 139^{6}$} \\
\hline & & & & $\mathrm{C} / 82$ & 300 & $2.5 \mathrm{~min}$ & \\
\hline \multirow{2}{*}{12} & \multirow{2}{*}{$\mathrm{OH}$} & \multirow{2}{*}{$\mathrm{OH}$} & \multirow{2}{*}{ Pentyl } & $\mathrm{B} / 69$ & - & $3 \mathrm{~h}$ & \multirow{2}{*}{$91-93 / 93-94^{19}$} \\
\hline & & & & $\mathrm{C} / 90$ & 300 & $2.5 \mathrm{~min}$ & \\
\hline \multirow[t]{2}{*}{13} & \multirow{2}{*}{$\mathrm{OH}$} & \multirow{2}{*}{$\mathrm{OH}$} & \multirow{2}{*}{ Heptyl } & $\mathrm{A} / 76$ & - & $2.5 \mathrm{~h}$ & \multirow{2}{*}{$97-99 / 95.5-96^{6}$} \\
\hline & & & & $\mathrm{C} / 86$ & 300 & $2.5 \mathrm{~min}$ & \\
\hline \multirow{2}{*}{14} & \multirow{2}{*}{$\mathrm{OH}$} & \multirow{2}{*}{$\mathrm{OH}$} & \multirow{2}{*}{ Nonyl } & $\mathrm{A} / 68$ & - & $3 \mathrm{~h}$ & \multirow{2}{*}{$\begin{array}{l}106-108 / \\
102-104^{20}\end{array}$} \\
\hline & & & & $\mathrm{C} / 83$ & 300 & $2.5 \mathrm{~min}$ & \\
\hline 15 & $\mathrm{OH}$ & $\mathrm{OH}$ & Undecyl & $\mathrm{A} / 70$ & - & $3 \mathrm{~h}$ & $108-109 / 97-98^{21}$ \\
\hline & Uח & $O H$ & Undecyi & $\mathrm{C} / 78$ & 300 & $3 \mathrm{~min}$ & \\
\hline 16 & $\mathrm{OH}$ & $\mathrm{OH}$ & Tridecyl & $\mathrm{A} / 72$ & - & $3 \mathrm{~h}$ & $110-112 / 98-99^{21}$ \\
\hline & & & & $\mathrm{C} / 89$ & 300 & $3 \min$ & \\
\hline 17 & $\mathrm{OH}$ & $\mathrm{OH}$ & & $\mathrm{A} / 74$ & - & $4 \mathrm{~h}$ & 209-210/211 \\
\hline 11 & Un & $O H$ & & $\mathrm{C} / 92$ & 300 & $3 \mathrm{~min}$ & $209-210 / 211$ \\
\hline 18 & $\mathrm{OH}$ & $\mathrm{OH}$ & & $\mathrm{A} / 79$ & - & $3.5 \mathrm{~h}$ & 187-188 \\
\hline 10 & Un & OH & & $\mathrm{C} / 86$ & 300 & $3 \mathrm{~min}$ & $18 /-188$ \\
\hline 19 & $\mathrm{OH}$ & $\mathrm{OH}$ & & $\mathrm{A} / 83$ & - & $3.5 \mathrm{~h}$ & $200-202$ \\
\hline & & & & $\mathrm{C} / 95$ & 300 & $3 \min$ & \\
\hline 20 & $\mathrm{OH}$ & $\mathrm{OH}$ & & C/90 & 300 & $3 \mathrm{~min}$ & $179-181$ \\
\hline & & & & $\mathrm{A} / 68$ & - & $4 \mathrm{~h}$ & $156 \quad 15022$ \\
\hline 21 & $\mathrm{OMe}$ & $\mathrm{OMe}$ & & $\mathrm{C} / 86$ & $300 \mathrm{w}$ & $3 \mathrm{~min}$ & $156-158$ \\
\hline 22 & $\mathrm{OMe}$ & $\mathrm{OMe}$ & & $\mathrm{A} / 78$ & - & $3 \mathrm{~h}$ & $133-135^{23}$ \\
\hline 22 & UlMe & OMle & & $\mathrm{C} / 89$ & $300 \mathrm{w}$ & $3 \mathrm{~min}$ & $133-135$ \\
\hline
\end{tabular}




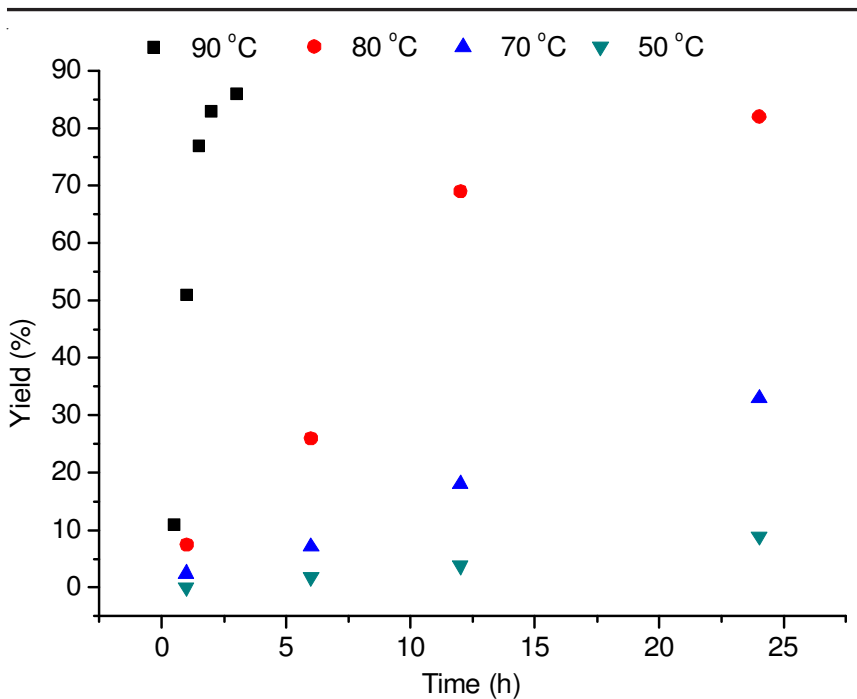

Fig. 1. Effect of reaction temperature on the yield of compound 20 at different time

that, as for substrates containing methoxy group, demethylation possibly caused by $\mathrm{BF}_{3} \cdot \mathrm{OEt}_{2}$ was not observed ${ }^{20-22}$.

In theory, acylation of a phenol with a carboxyl acid could possibly afford $O$-acylation and $C$-acylation products at the presence of $\mathrm{BF}_{3} \cdot \mathrm{OEt}_{2}$. To verify the possibility of $O$-acylation, butanoic acid was then selected to react with catechol in different ratios. The reaction was monitored by TLC and results are shown in Table-2. Our data revealed that the para- $C$-acylation product is observed at the ratio of $\mathrm{BF}_{3} \cdot \mathrm{OEt}_{2}$ to catechol being over 1:1. At the ratio lower than 1:1, $O$-acylation product was once expected to be given when butanoic acid is treated with $\mathrm{BF}_{3} \cdot \mathrm{OEt}_{2}$ before the addition of catechol. However, no $O$-acylation product was observed in any case, indicating that this condensation reaction is chemoselective.

As shown in Table-1, these reactions furnished 3,4dihydroxyphenyl ketones (10-17, 21-22) in good yields, which were confirmed by melting points. While compounds 18-20 with melting points not reported previously were further characterized by elemental analyses, MS and ${ }^{1} \mathrm{H}$ NMR spectra. In addition, the structure of compound $\mathbf{1 4}$ was also confirmed by single crystal X-ray crystallography (Fig. 2). It is noted that no 2,3-dihydroxyphenyl ketones was isolated, revealing that the acyl radical enters predominantly the para position under the influence of $\mathrm{BF}_{3} \cdot \mathrm{OEt}_{2}$. The regioselectivity was further supported by our literature survey. Several direct acylation of phenol and catechol, using $\mathrm{BF}_{3} \cdot \mathrm{OEt}_{2}$ as a promoter, also gave para-hydroxyaryl ketone derivatives ${ }^{10,12}$.

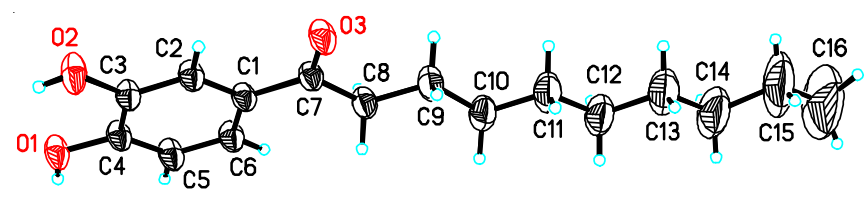

Fig. 2. Single crystal structure of compound $\mathbf{1 4}$

However, to our surprise, Hossein Naeimi et al. ${ }^{13,14}$ reported a quite different result. They claimed that acylation of phenol and naphthol derivatives with acetic acid gave regioselectively ortho acylated products in the presence of $\mathrm{BF}_{3} \cdot \mathrm{OEt}_{2}$ under microwave irradiation. To check their reported results, we then treated catechol with acetic acid as the description of Hossein Naeimi. Unfortunately, no ortho acylated product (2,3dihydroxyacetophenone) was observed and the isolated product is identified as 3,4-dihydroxyace-tophenone (10, the para acylated product), suggesting that the para-directing effect of $\mathrm{BF}_{3} \cdot \mathrm{OEt}_{2}$ would not change with whether or not having microwave irradiation. Nevertheless, it must be admitted that the reaction time is greatly shortened.

With the above mentioned observations, we are able to propose a plausible mechanism to understand the highly chemoselective and regionselective acylation of catechol at the presence of $\mathrm{BF}_{3} \cdot \mathrm{OEt}_{2}$ (Scheme-II). It is well known that the powerful electron withdrawing effect of carbonyl group leads to a significant decrease in electron cloud around $\mathrm{OH}$ in carboxylic acid. Therefore, in comparison with carboxylic acid, $\mathrm{BF}_{3} \cdot \mathrm{OEt}_{2}$ prefers to react with catechol, giving the Lewis adduct 5. Based on this hypothesis, reaction of a carboxylic acid with $\mathrm{BF}_{3} \cdot \mathrm{OEt}_{2}$ occurs only when the ratio of $\mathrm{BF}_{3} \cdot \mathrm{OEt}_{2}$ to catechol is over 1:1 and results in the formation of an acylating agent 4. This was evidenced by observations in acylation of catechol with butanoic acid (Table-2). In the Lewis adduct $\mathbf{5}$, the rotation of $\mathrm{C}-\mathrm{O}$ single bond causes a fast migration of $\mathrm{BF}_{3}$ between two hydroxyl groups to give species 6 with occupation numbers of $\mathrm{BF}_{3}$ being 0.5 at both sites, which causes a significant increase in steric hindrance around ortho-positions of hydroxyl groups. The steric effects of the boron trifluoride catechol complex (6) disfavor the attack of species $\mathbf{4}$ at ortho-positions, resulting in the para-directing effect of $\mathrm{BF}_{3} \cdot \mathrm{OEt}_{2}$. Therefore, the para-isomer $\mathbf{2}$ is predominantly given and the orthoanalogue, if any, is too little to be observed. On the other hand, the positive charge atmosphere around hydroxyl groups in complex $\mathbf{6}$ blocks from the access of acylium ion 4 to form $O$ acylated product 9.

ACYLATION OF CATECHOL WITH BUTANOIC ACID AT $90^{\circ} \mathrm{C}$

\begin{tabular}{|c|c|c|c|c|c|}
\hline \multirow[b]{2}{*}{ Entry } & \multirow[b]{2}{*}{$\begin{array}{l}\text { Catechol } \\
(\mathrm{mmol})\end{array}$} & \multirow[b]{2}{*}{$\begin{array}{l}\text { Butanoic acid } \\
\quad(\mathrm{mmol})\end{array}$} & \multirow[b]{2}{*}{$\begin{array}{c}\mathrm{BF}_{3} \cdot \mathrm{OEt}_{2} \\
(\mathrm{mmol})\end{array}$} & \multicolumn{2}{|c|}{ Possible product } \\
\hline & & & & para-C-acylation & $O$-acylation \\
\hline 1 & 2 & 11 & 1 & not observed & not observed \\
\hline 2 & 2 & 11 & 2 & not observed & not observed \\
\hline 3 & 2 & 11 & 3 & observed & not observed \\
\hline 5 & 2 & 11 & 8 & observed & not observed \\
\hline
\end{tabular}




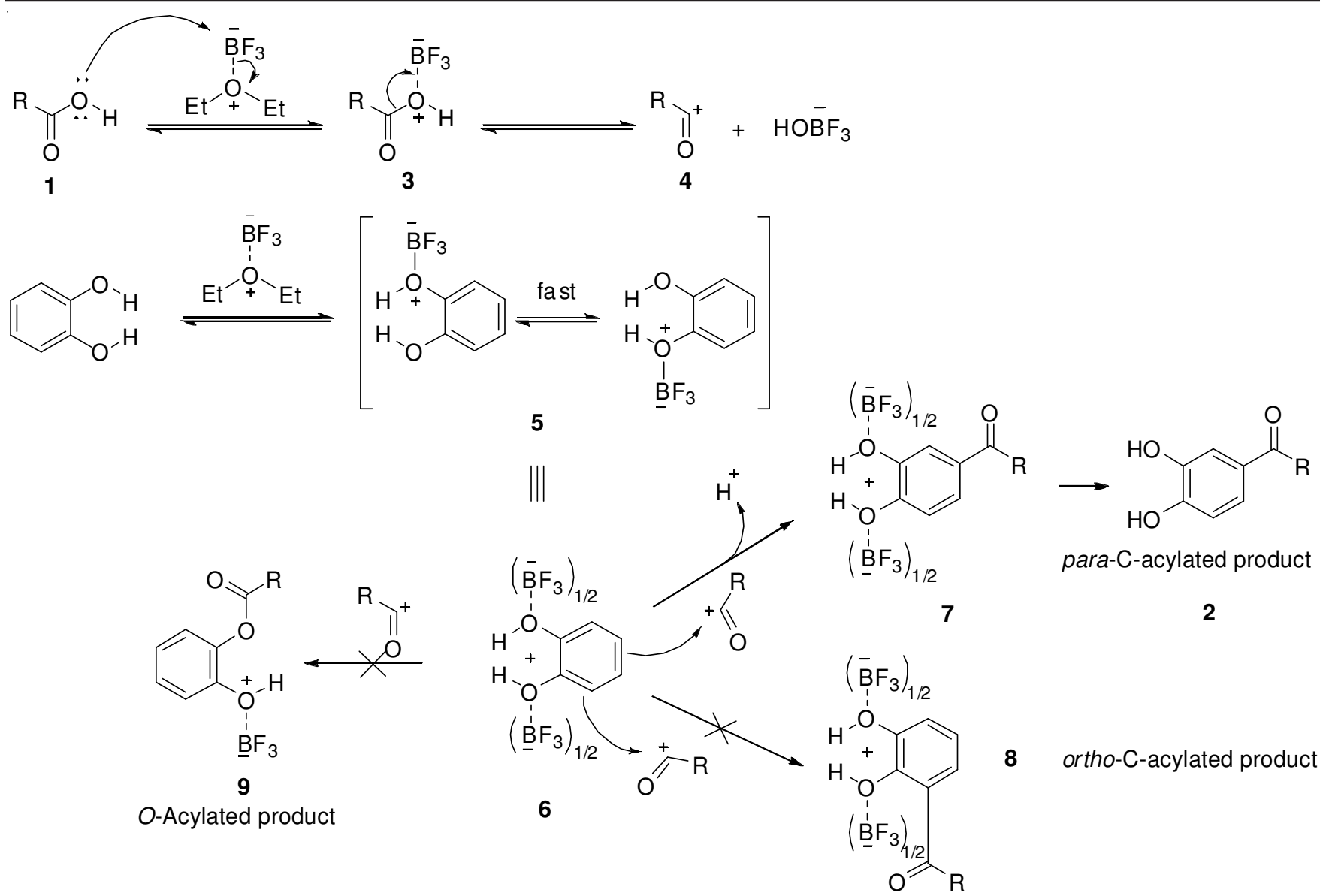

Scheme-II: Mechanism of para-selective acylation of phenol catalyzed by $\mathrm{BF}_{3} \cdot \mathrm{OEt}_{2}$

\section{Conclusion}

Reaction of phenols with free carboxylic acid in $\mathrm{BF}_{3} \cdot \mathrm{OEt}_{2}$ shows high chemoselectivity and regioselectivity, which predominantly give the para-C-acylated product whether or not having microwave irradiation. This para-directing effect of $\mathrm{BF}_{3} \cdot \mathrm{OEt}_{2}$ may attribute to the large steric hindrance of the boron trifluoride-phenolic hydroxyl group complex. Nevertheless, the reaction time is greatly shortened with the microwave assistance. No demethylation was observed in the case of phenol ethers.

\section{ACKNOWLEDGEMENTS}

This work is financed by grants from National Natural Science Foundation (grant No. 81273382) of China and by a Project supported by Hunan Provincial Natural Science Foundation of China (grant No. 13JJ2030)

\section{REFERENCES}

1. J.H. Cheng, C.F. Hung, S.C. Yang, J.P. Wang, S.J. Won and C.N. Lin, Bioorg. Med. Chem., 16, 7270 (2008).

2. N.A. Shakil, M.K. Singh, M. Sathiyendiran, J. Kumar and J.C. Padaria, Eur. J. Med. Chem., 59, 120 (2013).

3. Z.A. Kaplancikli, G. Turan-Zitouni, A. Özdemir, Ö. Devrim Can and P. Chevallet, Eur. J. Med. Chem., 44, 2606 (2009).

4. S. Shenvi, K. Kumar, K.S. Hatti, K. Rijesh, L. Diwakar and G.C. Reddy, Eur. J. Med. Chem., 62, 435 (2013).

5. N. Fokialakis, X. Alexi, N. Aligiannis, D. Siriani, A.K. Meligova, H. Pratsinis, S. Mitakou and M.N. Alexis, Bioorg. Med. Chem., 20, 2962 (2012).
6. E. Miller, W.H. Hartung, H.J. Rock and F.S. Crossley, J. Am. Chem. Soc., 60, 7 (1938).

7. R. Murashige, Y. Hayashi, S. Ohmori, A. Torii, Y. Aizu, Y. Muto, Y. Murai, Y. Oda and M. Hashimoto, Tetrahedron, 67, 641 (2011).

8. A.M. Simion, I. Hashimoto, Y. Mitoma, N. Egashira and C. Simion, Synth. Commun., 42, 921 (2012).

9. I.V. Kozhevnikov, Appl. Catal. A, 256, 3 (2003)

10. N. Buu-Hoi and J. Seailles, J. Org. Chem., 20, 606 (1955).

11. N.P. Buu-Hoï and N.D. Xuong, J. Org. Chem., 26, 2401 (1961).

12. K. Wähälä and T.A. Hase, J. Chem. Soc., Perkin Trans. I, 3005 (1991).

13. H. Naeimi and L. Moradi, Bull. Chem. Soc. Jpn., 78, 284 (2005).

14. H. Naeimi and L. Moradi, J. Mol. Catal. Chem., 256, 242 (2006).

15. Z.P. Xiao, D.H. Shi, H.Q. Li, L.N. Zhang, C. Xu and H.L. Zhu, Bioorg. Med. Chem., 15, 3703 (2007).

16. Z.P. Xiao, T.W. Ma, W.C. Fu, X.C. Peng, A.H. Zhang and H.L. Zhu, Eur. J. Med. Chem., 45, 5064 (2010).

17. Z.P. Xiao, X.D. Wang, Z.Y. Peng, S. Huang, P. Yang, Q.S. Li, L.H. Zhou, X.J. Hu, L.J. Wu, Y. Zhou and H.L. Zhu, J. Agric. Food Chem., 60, 10572 (2012).

18. M. Gopalakrishnan, P. Sureshkumar, V. Kanagarajan and J. Thanusu, Catal. Commun., 6, 753 (2005).

19. R.W. Stoughton, R. Baltzly and A. Bass, J. Am. Chem. Soc., 56, 2007 (1934).

20. T.B. Stolwijk, E.J.R. Sudholter and D.N. Reinhoudt, J. Am. Chem. Soc., 111, 6321 (1989).

21. R.D. Haworth and D. Woodcock, J. Chem. Soc., 999 (1946).

22. M. Medarde, R.P.-L. de Clairac, J.L. López and A.S. Feliciano, J. Nat. Prod., 57, 1136 (1994).

23. V. Percec, B.C. Won, M. Peterca and P.A. Heiney, J. Am. Chem. Soc., 129, 11265 (2007). 